\title{
Uma Análise da Demanda por Combustíveis Através do Modelo Almost Ideal Demand System para Pernambuco ${ }^{1}$
}

\author{
Edilberto Tiago de Almeida², Wellington Ribeiro Justo ${ }^{3}$, \\ Monaliza Ferreira de Oliveira ${ }^{4}$ e Carla Calixto da Silva ${ }^{5}$
}

Resumo: O mercado de combustíveis tem sido amplamente estudado sob várias perspectivas, desde a questão da assimetria e transmissão de preços, formação de cartéis, dinâmica de preços atrelada às flutuações na economia internacional, sistemas de demanda, entre outras. Neste sentido, este artigo tem como objetivo estimar um sistema de demanda para gasolina comum, etanol hidratado e óleo diesel via modelo (LA-AIDS) Linear Approximation Almost Ideal Demand System com dados de séries temporais trimestrais para o período de 2001 a 2015 para o estado de Pernambuco. As estimações foram feitas por meio do método (SUR) Seemingly Unrelated Regressions. Os resultados encontrados são semelhantes aos observados na literatura, no sentido em que apontam para a inelasticidade-preço da demanda da gasolina e diesel, o que é esperado dada a essencialidade dos bens. Também foi possível verificar que a demanda por etanol é elástica por ter elasticidade-preço marshalliana maior que um em valor absoluto, convergindo para os resultados já encontrados em outros estudos.

Palavras-chaves: Demanda; Combustíveis; LA-AIDS; SUR.

Abstract: The fuel market has been widely studied at several perspectives, from the issue of asymmetry and transmission prices, cartels, dynamics linked to price fluctuations in the international economy, demand systems, among others. Thus, this paper aims to estimate a demand system for regular gasoline, hydrous ethanol and diesel via (LA-AIDS) Linear Approximation Almost Ideal Demand System with quarterly time series data for the period 2001-2015 in Pernambuco State (Brazil). The estimates were made using (SUR) Seemingly Unrelated Regressions. The results are similar to those observed in the literature, pointing to the inelasticity-price of demand for gasoline and diesel, which is

1. Data de submissão: 10 de fevereiro de 2016. Data de aceite: 19 de julho de 2016.

2. Programa de Pós-graduação em Economia - PPGECON da Universidade Federal de Pernambuco. Caruaru, Pernambuco, Brasil. E-mail: edilbertotiago@hotmail.com

3. Universidade Regional do Cariri. Crato, Ceará, Brasil. E-mail: justowr@yahoo.com.br

4. Universidade Federal de Pernambuco. Caruaru, Pernambuco, Brasil. E-mail: monaliza.ferr@gmail.com

5. Universidade Federal da Paraíba. João Pessoa, Paraíba, Brasil. E-mail: carla_calixto.s@hotmail.com 
expected given the essentiality of the assets. It was also observed that the demand for ethanol is elastic because of Marshallian price elasticity greater than one in absolute value, leading to the results already found in other studies.

Key-words: Demand; Fuel; LA-AIDS; SUR.

DOI - http://dx.doi.org/10.1590/1234-56781806-94790540406

Classificação JEL: D11, D12, D18.

\section{Introdução}

O mercado de combustíveis vem passando por mudanças significativas. No contexto atual da economia mundial, o preço do petróleo, por exemplo, é uma variável que pode afetar os mercados, principalmente o financeiro. Diante disto, a matriz energética de um país possui grande importância para o seu crescimento econômico. Por este motivo, quanto maior a diversificação, melhor. No caso do Brasil, é possível observar que o País vem buscando a diversificação da sua matriz energética nos últimos anos, como pode ser visto no Balanço Energético Nacional (BEN, 2015).

O debate sobre as fontes alternativas de energia está correlacionado com questões de desenvolvimento sustentável e as ampliações das fontes de energia possuem grande influência na dinâmica de mercado. Mudanças relacionadas ao preço do petróleo podem afetar diversas atividades, principalmente no caso brasileiro, em que a maior parte da produção é escoada pelo modal rodoviário (BETARELLIJÚNIOR e DOMINGUES, 2013). O biocombustível, com destaque para o etanol, tem se mostrado uma alternativa aos combustíveis fósseis; nesta perspectiva, como destacado por Calle e Walter (2006), pode-se dizer que ocorre o aumento da segurança energética.

Dado a importância deste mercado, seu dinamismo tem sido amplamente estudado sobre várias perspectivas, desde a questão da assimetria e transmissão de preços, formação de cartéis, variabilidade de preços atrelada às flutuações na economia internacional e outras (SANTOS, 2012; CARDOSO e BITTENCOURT, 2014). O setor também tem sido alvo de políticas fiscais específicas nos últimos anos com o objetivo de conter a inflação, e este é um dos argumentos usados por pesquisadores que elencam os motivos que contribuíram para a atual crise fiscal brasileira.

Na perspectiva da demanda por combustíveis no Brasil, em especial para a gasolina e o etanol, os estudos recentes buscam explicar a relação entre estes bens no intuito de encontrar o grau de substituição entre eles. Esta abordagem ganha ênfase se analisada conjuntamente com questões de sustentabilidade, assunto que tem permeado o centro de várias discussões. A gasolina como combustível não renovável tende à escassez em datas futuras, apesar de esta óptica não formar um consenso na literatura (CARDOSO e BITTENCOURT, 2014).

O etanol, no entanto, é um combustível substituto e, além disto, o comportamento do consumidor frente à escolha entre os dois bens é um dos problemas centrais neste contexto, que pode determinar a intensidade dos efeitos de políticas direcionadas especificamente para o setor. Como destacam Cardoso et al. (2013), o etanol só consegue competir com a gasolina nos centros produtores ou nas proximidades destes. Ou seja, a demanda é reprimida em alguns estados apesar dos vários benefícios frente ao consumo da gasolina. Os autores destacam, ainda, que o etanol é competitivo somente sazonalmente, nos períodos de safra em alguns casos. 
Goldemberg e Guardabassi (2009) apontam as vantagens no Brasil para produção do etanol destacando os aspectos: balanço energético fóssil, redução de emissão de $\mathrm{CO}_{2}$ relativamente à gasolina e as grandes extensões territoriais. Nesta abordagem são considerados indicadores ambientais e fatores tecnológicos, isto é, no segundo caso, a implementação da tecnologia alternativa necessária para produção, e se os custos possibilitariam a entrada no mercado com preços competitivos.

Pode-se ainda considerar como fator de influência sobre a demanda dos combustíveis no Brasil o aumento da frota de veículos, o que está correlacionado com diversas externalidades negativas. Silva et al. (2010) apontam o aumento da competição no mercado de combustíveis a partir de 2003 com a entrada dos veículos flex-fuel. Nesta óptica, existem estudos na literatura com objetivo de estimar os impactos da entrada destes veículos. Para este tipo de análise, geralmente são utilizadas variáveis dummies.

Existe uma gama de trabalhos com objetivo de estimar elasticidades para os combustíveis para o Brasil utilizando diferentes métodos. Como será detalhado nas próximas seções, os resultados obtidos a partir destas metodologias convergem, de modo geral, no sentido em que apontam para a inelasticidade-preço da demanda por gasolina (ver, por exemplo, ALVES e BUENO, 2003; ROPPA, 2005; SANTOS, 2012) e para elasticidade-preço da demanda por etanol (RANDOW et al., 2010; SOUZA, 2010; CARDOSO et al., 2013; CARDOSO e BITTENCOURT, 2014). A presente pesquisa utiliza o (LA-AIDS) Linear Approximation Almost Ideal Demand System para as estimações de demanda no sentido de obter evidências a partir de uma estrutura formalmente pautada na teoria sobre a volatilidade da demanda por combustíveis.

Neste sentido, este artigo tem como objetivo estimar um sistema de demanda para gasolina comum, etanol hidratado e óleo diesel - três dos quatro principais combustíveis no cenário nacional, de acordo com Santos (2012) - via modelo LA-AIDS para o estado de Pernambuco. Obter as elasticidades e contribuir para literatura sobre o tema ao incorporar uma metodologia fundamentada na teoria do consumidor, preservando, deste modo, todos os seus pressupostos.

Além desta introdução, este artigo está dividido em cinco seções. Na parte que segue analisam-se sinteticamente alguns aspectos da matriz energética e do mercado de combustíveis no Brasil e em Pernambuco. A seção três tem como objetivo ressaltar os principais trabalhos empíricos neste contexto. Na seção quatro apresentam-se o modelo teórico e os métodos usados nas estimações e, posteriormente, são ressaltados os resultados seguidos das considerações finais.

\section{Mercado de combustíveis e matriz energética}

De acordo com Randow et al. (2010), as crises do petróleo em 1973 e 1979 revelaram a fragilidade dos países que têm sua matriz energética completamente baseada no petróleo e seus derivados. Neste contexto, nas últimas quatro décadas ocorreram ampliações de novas fontes de energia. Na última década, o consumo de energia primária no mundo cresceu, em média, 1,9\%, e em 2015 a taxa de crescimento foi de 1\% (BP, 2016). Ainda de acordo com o relatório da British Petroleum (2016), as economias emergentes representaram $97 \%$ do aumento do consumo global de energia primária.

No Brasil, como mostra o Balanço Energético Nacional (BEN, 2015), que tem como ano base 2014, a participação na oferta de energia interna de fontes renováveis, apesar da diversificação observada desde a década de 1980, vem decrescendo desde 2010 em termos relativos. Sendo $60,6 \%$ desta oferta composta por energia não renovável em 2014 e, em 2010, era de 55,3\%. A participação do petróleo e seus derivados se mantiveram relativamente constantes na última década e os derivados da cana de açúcar ganharam espaço, em média, no mesmo período. $\mathrm{O}$ mercado de combustíveis brasileiro, como destaca Santos (2012), pode ser tido como diferenciado pela diversidade de combustíveis, sendo 
os principais gasolina, etanol, gás natural e óleo diesel.

De acordo com o Departamento Nacional de Trânsito - Registro Nacional de Veículos Automotores (Denatran-Renavam), o Brasil tinha, em outubro de 2015, frota de 90.003 .877 veículos $(0,44$ per capita), em que a maior parte é de automóveis (49.508.411) - em termos percentuais, isto equivale a $55,01 \%$ do total. O Nordeste possui a terceira maior frota para o mesmo período no cenário nacional (total de 15.036.030, ou 0,26 per capita, sendo 6.030.449 automóveis) ficando atrás da região Sudeste (total de 44.156.853, ou 0,51 per capita, sendo 27.197 .841 automóveis) e da região Sul (total de 17.922.018, em termos per capita, 0,61, sendo 10.656.525 automóveis).

Além dos automóveis, a frota nacional é composta por $22,28 \%$ de motocicletas, $2,93 \%$ de caminhões, 7,26\% de caminhonetes, $0,65 \%$ de caminhão-trator, entre outras categorias com participações menos expressivas. Posto isto, os estudos de demanda para este mercado encontram respaldo dada a dimensão deste e a expressiva participação de veículos leves. Foi possível observar que, apesar de o Sudeste possuir a maior frota dentre as regiões do Brasil, a região Sul possui mais veículos per capita. Além disto, a região Sudeste e a região Sul, em termos per capita, possuem mais veículos do que o País como um todo, enquanto o Nordeste está abaixo do valor obtido nacionalmente.

Com respeito à competição no mercado, Santos (2012) destaca que a gasolina ainda é o principal combustível, embora a concorrência com o etanol e o GNV tenha aumentado. Ainda neste contexto, o autor enfatiza que, no curto prazo, o diesel não é um concorrente potencial da gasolina, dada a composição da frota de veículos no Brasil, sendo usado somente por veículos de grande porte. Entretanto, isto não implica que o diesel não é importante para os estudos sobre a gasolina, mas a interpretação de elasticidades-preço cruzadas perde o sentido neste caso.

A Figura 1 mostra a evolução das vendas mensais pelas distribuidoras de gasolina comum, etanol hidratado e óleo diesel no Brasil no perí-

Figura 1. Vendas mensais pelas distribuidoras de gasolina comum, etanol hidratado e óleo diesel no Brasil de janeiro de 2000 a agosto de 2015

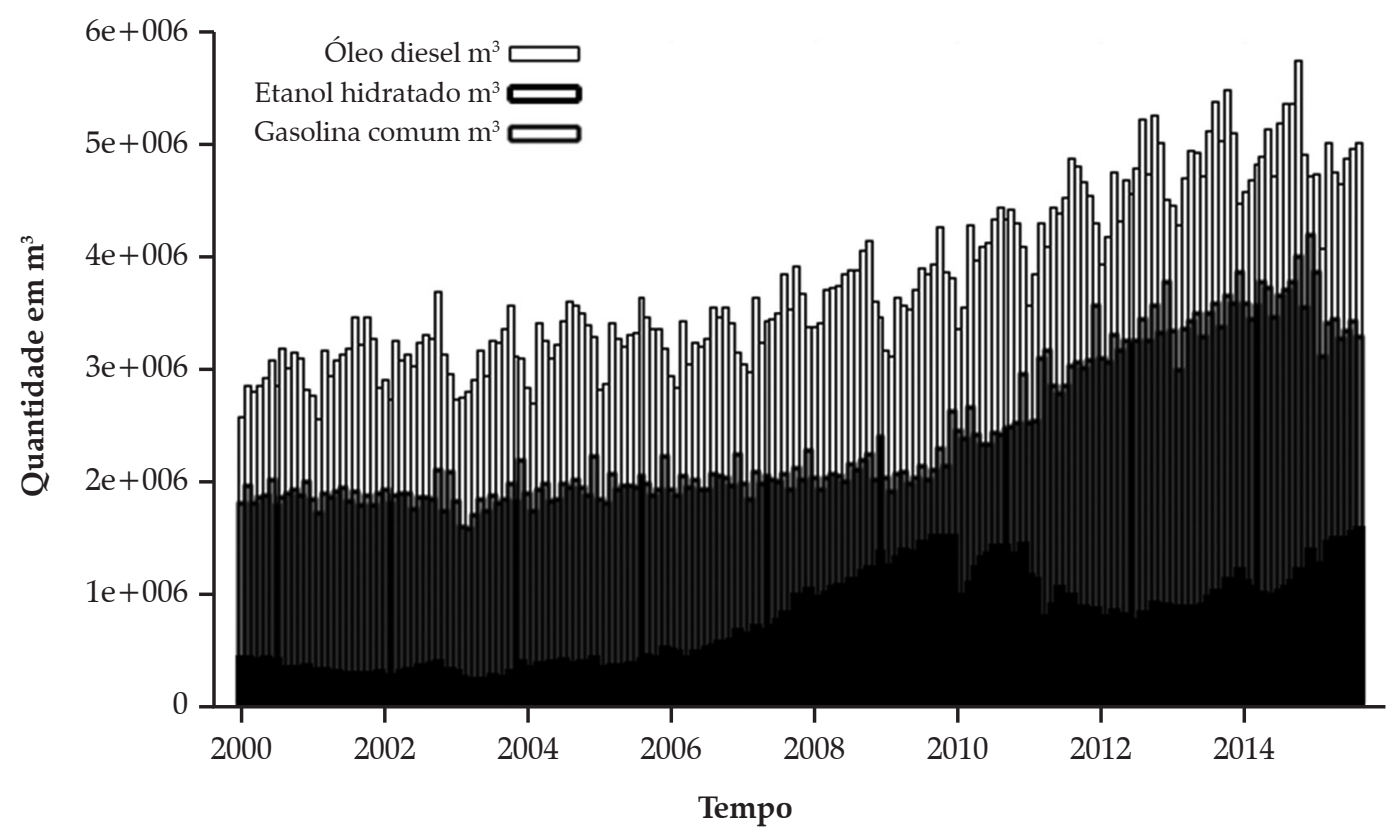

Nota: Até 2006 as vendas e o consumo próprio das distribuidoras são incluídos. Posteriormente, a partir de 2007, apenas as vendas estão incluídas. Fonte: Elaboração própria com dados da ANP. 
odo de janeiro de 2000 a agosto de 2015. Como mostra o gráfico, as vendas dos três combustíveis analisados possuem tendência ascendente no período. Ressalta-se, entretanto, que no caso do etanol hidratado observa-se uma relativa suavização desta trajetória a partir de 2010.

Como destacado anteriormente, com base em Goldemberg e Guardabassi (2009), por vários fatores o etanol pode desempenhar um importante papel no cenário nacional. Neste sentido, podem-se destacar duas regiões produtoras de etanol, o Centro-Sul e a região Norte-Nordeste (SIGNORINI e MARJOTTA-MAISTRO, 2007). De acordo com o Ministério da Agricultura, Pecuária e Abastecimento - Sistema de Acompanhamento de Produção Canavieira (Mapa-Sapcana) foram produzidos, na safra 2015/2016, em Pernambuco, $26.260 \mathrm{~m}^{3}$ de etanol - deste total, $6.304 \mathrm{~m}^{3}$ são de etanol anidro e $19.956 \mathrm{~m}^{3}$, de etanol hidratado. Em termos de produção entre os estados do Nordeste, Pernambuco obteve a segunda maior produção de cana-de-açúcar no mesmo período, perdendo apenas para a Bahia. Todavia, na produção de etanol, ocupa o terceiro lugar no ranking, ficando atrás de estados como Bahia e Paraíba. Já com relação à produção de açúcar, ocupou o posto de maior produtor na região para o período.

De acordo com o Departamento Estadual de Trânsito de Pernambuco (Detran-PE), Pernambuco possuía uma frota registrada, em outubro de 2015, de 1.248.943 automóveis (veículos leves), 335.394 veículos de carga (caminhão e caminhonete), 37.637 ônibus e micro-ônibus, 1.025 .416 motocicletas e motonetas e 81.834 não enquadrados nas classificações anteriores (outros). Em 1990, Pernambuco tinha frota registrada de 391.141 veículos; em termos per capita isso é equivalente a 0,05 , e em outubro de 2015 este número chegou a 2.729.224, ou 0,29 em termos per capita. No período de 1990 a 2015, o estado apresentou crescimento significativo da frota de veículos, tanto em termos absolutos quanto per capita. Além disto, também é possível observar que Pernambuco, em termos per capita, possui mais veículos que a região Nordeste como um todo, embora ainda fique abaixo do nível nacional.
Assim, com a expansão observada e a importância deste tipo transporte, não só em Pernambuco, mas como destacado, para o Brasil, estudar o comportamento da demanda por combustíveis pode ajudar na formulação de políticas públicas para este mercado na economia pernambucana. Tal como apresentado na Figura 1, na Figura 2, a seguir, apresentam-se as vendas mensais pelas distribuidoras de gasolina comum, etanol hidratado e óleo diesel para o estado de Pernambuco no mesmo período. Percebe-se que as trajetórias das vendas em Pernambuco seguem a tendência nacional; todavia, o hiato diesel-gasolina é menor no estado relativamente ao agregado. Além disto, assim como no âmbito nacional, as vendas (proxy para demanda pelos respectivos combustíveis) de etanol desaceleraram após 2010.

A Figura 3, a seguir, mostra a trajetória dos preços de revenda dos três combustíveis para Pernambuco. Percebe-se uma tendência de aumento dos valores. As séries estão representadas em nível, o que torna perceptível o componente sazonal. Também é possível observar que a série menos volátil é a de preços de revenda do óleo diesel.

Contudo, pode-se sintetizar a cadeia de combustíveis automotivos, de acordo com Conselho Administrativo de Defesa Econômica (Cade), em duas grandes etapas antes do alcance ao consumidor final. Uma destas é a produção, em que estão incluídas as refinarias de petróleo (Petrobrás e Privadas), centrais petroquímicas, as usinas/destilarias, os formuladores ${ }^{6}$, e exportadores e importadores. Já a segunda etapa é a de distribuição, ou seja, os distribuidores, os revendedores de varejo e os Transportadores-Revendedores-Retalhistas (TRRs). Outra característica importante sobre esta cadeia é que no Brasil não há verticalização no canal de distribuição varejista; esta é observada somente no canal de distribuição atacadista, ou seja, neste último caso, um agente econômico detém vários estágios da produção.

6. Empresa autorizada que produz gasolina e óleo diesel a partir da mistura de correntes de hidrocarbonetos adquiridos no mercado, diferente das refinarias que usam correntes de hidrocarbonetos de produção própria (CADE, 2014). 
Figura 2. Vendas mensais pelas distribuidoras de gasolina comum, etanol hidratado e óleo diesel em Pernambuco de janeiro de 2000 a agosto de 2015

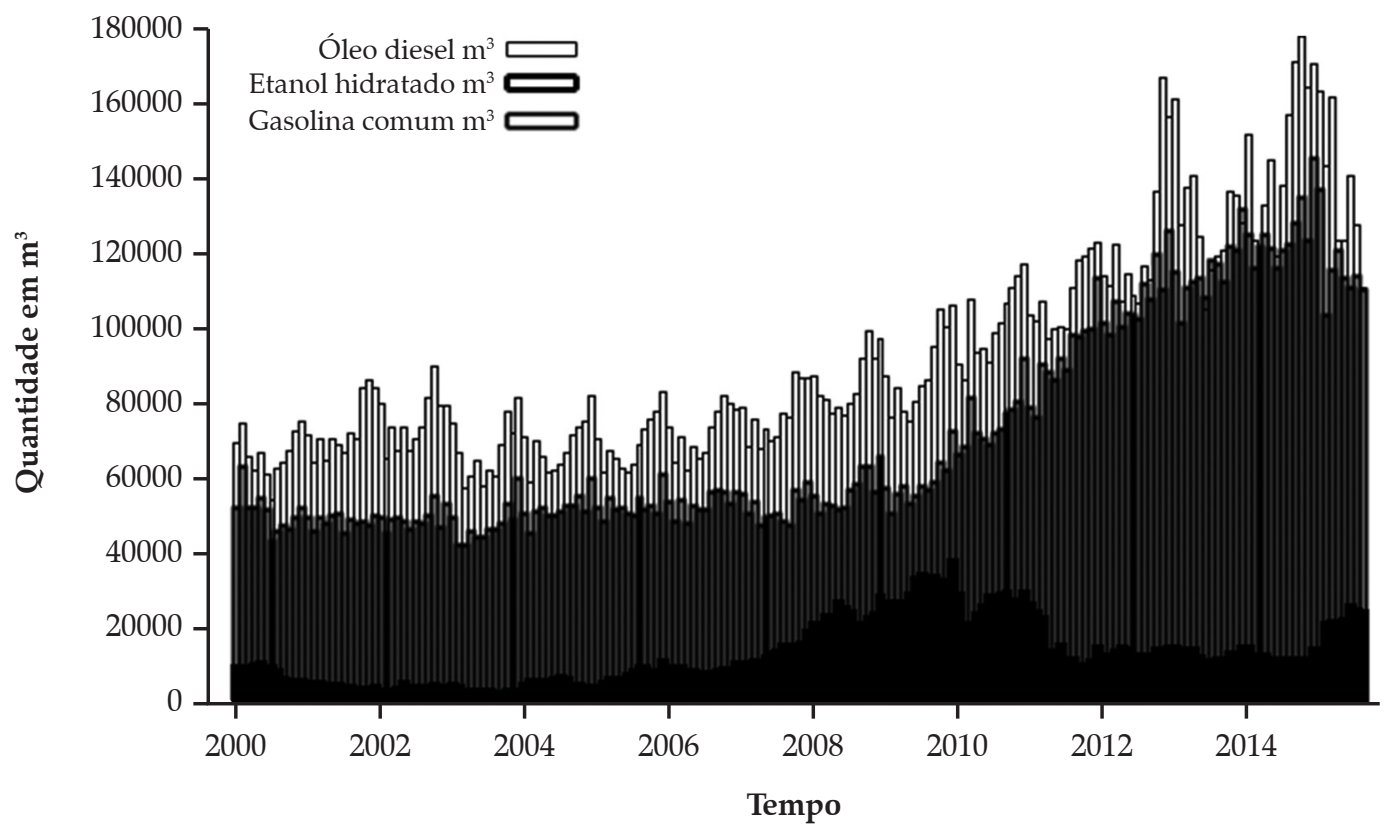

Nota: Até 2006, as vendas e o consumo próprio das distribuidoras são incluídos, posteriormente, a partir de 2007, apenas as vendas estão incluídas. Fonte: Elaboração própria com dados da ANP.

Figura 3. Preço de revenda da gasolina comum, etanol hidratado e óleo diesel, em Pernambuco, de julho de 2001 a agosto de 2015

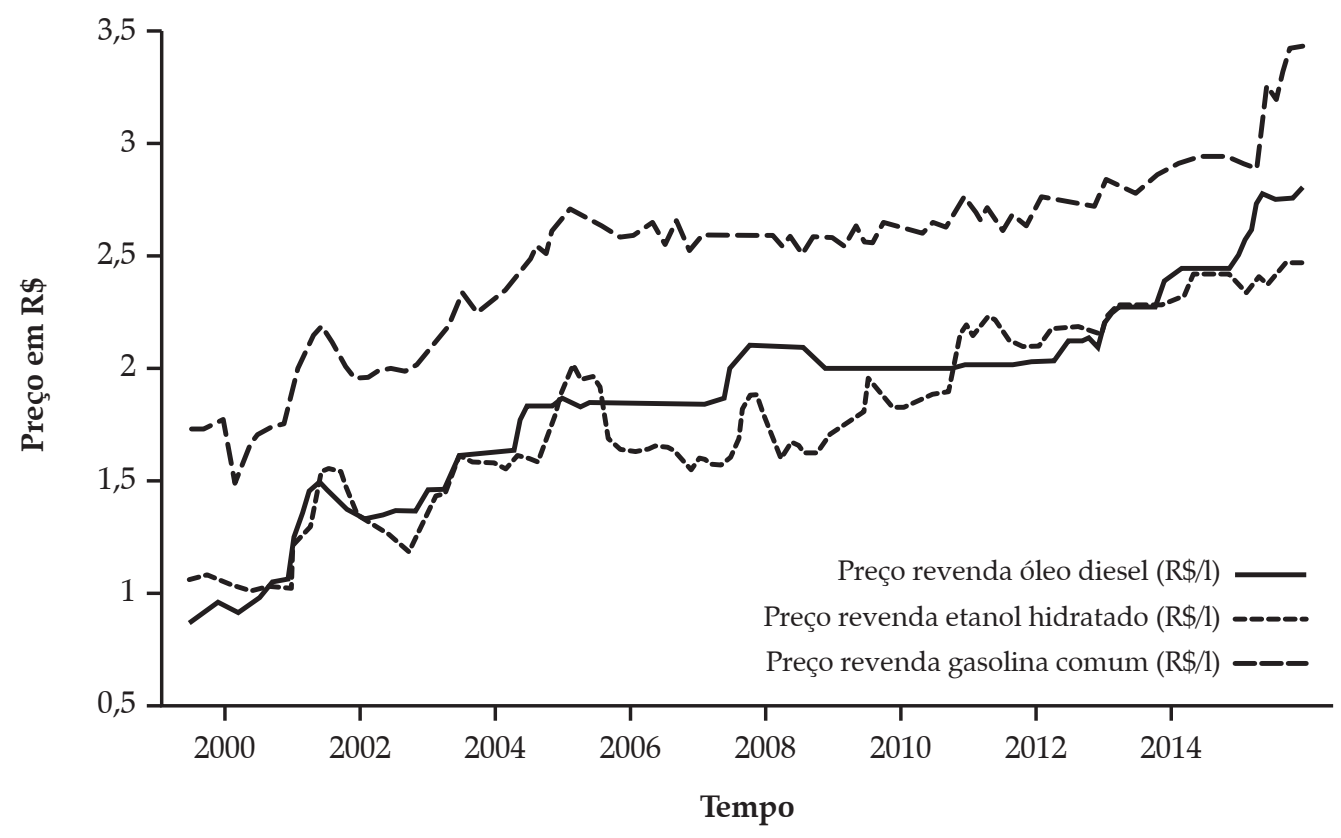

Fonte: Elaboração própria com dados da ANP. 


\section{Revisão de literatura}

Os estudos de demanda por combustíveis no geral utilizam três variáveis independentes básicas para explicar o comportamento da demanda de mercado, são elas: o preço do bem, o preço do bem substituto/complementar e a renda. Como destaca Silva (2008), estudos nesta área são importantes no sentido em que diversos bens e serviços podem ter seus preços afetados por choques nos preços dos combustíveis. Entretanto, a depender do objetivo da pesquisa, uma gama de variáveis explicativas pode ser incluída com o objetivo de controlar determinadas características específicas do comportamento da demanda. Nesta perspectiva, existem diversos estudos empíricos na literatura que abordam tal problemática, com diferentes metodologias e variáveis explicativas, tanto para o cenário internacional ${ }^{7}$ quanto para o nacional ${ }^{8}$.

Os diversos métodos econométricos utilizados nas estimações das funções demanda por combustíveis motivaram Dahl e Sterner (1991) a elencar as diferentes técnicas e seus respectivos resultados. Além das diferentes especificações dos modelos, os autores evidenciaram um conjunto diversificado de variáveis exógenas que vão desde os componentes clássicos da demanda até variáveis de estoques e frota de veículos, entre outros controles. Os autores fizeram uma comparação dos diversos estudos sobre a demanda por gasolina e constataram que este é um bem que possui demanda inelástica ao preço no curto prazo e no longo prazo. Nesta abordagem, Cardoso et al. (2013) vai além ao enfatizar que, mundialmente, a demanda por combustíveis leves pode ser sintetizada e classificada como

7. Para verificar alguns dos estudos mais importantes na literatura, ver Espey (1998).

8. De acordo com Cardoso et al. (2013), exceto o Brasil, um pequeno grupo de países possuem substitutos para a gasolina, na concepção dos combustíveis leves. Além do estudo de Cardoso et al. (2013), podem-se destacar os seguintes trabalhos para o Brasil: Burnquist e Bacchi (2002), Roppa (2005), Nappo (2007), Schünemann (2007), Serigati et al. (2010), Randow et al. (2010), Souza (2010), Freitas e Kaneko (2011), Santos (2012), Santos e Faria (2012), Anna e Bastos (2014). inelástica no curto e longo prazo, embora mais fracamente no segundo caso.

Em países em desenvolvimento, Ramanathan (1999) ressalta que os derivados do petróleo possuem influencia na balança de pagamentos e no crescimento econômico, ou seja, pode se tornar um entrave na dinâmica da economia e deixar os países suscetíveis a choques nos preços das commodities, como nos períodos dos choques de petróleo. Neste sentido, estimaram equações de demanda por gasolina na Índia para o período de 1972 a 1994. No estudo foram utilizados modelos de séries temporais cointegrados e vetores de correção de erros, obtendo-se que a demanda por gasolina na Índia é inelástica ao preço no curto prazo, seguindo, deste modo, os resultados dos estudos empíricos para outros países.

Cheung e Thomson (2004) estimaram as elasticidades-preço e renda para China no período de 1980 e 1990. Eles constataram, por meio de séries temporais cointegradas, assim como no caso de Ramanathan (1999), que a demanda por gasolina na China é inelástica ao preço no curto prazo. Com relação à elasticidade-renda da demanda, os autores concluíram que, no curto prazo, a quantidade demandada é mais sensível a variações na renda que no longo prazo.

Na abordagem de modelos de séries temporais cointegrados, Nappo (2007), utilizando séries mensais para o período de 1994 a 2006, investigou as influências da entrada dos veículos flex-fuel no Brasil sobre a demanda por gasolina. Os resultados encontrados mostraram que a demanda por gasolina após 2003, ou seja, pós-flex, tornou-se mais elástica ao preço. Essa comparação periódica foi feita através de variáveis binárias. Farina et al. (2010), em análise do período de 2001 a 2009 para o Brasil, concluíram que a demanda por etanol é elástica ao preço no curto prazo - os resultados também foram obtidos com base em séries temporais mensais cointegradas.

Serigati et al. (2010) também estimaram equações de demanda e oferta simultaneamente para o etanol no Brasil por (3SLS) Three-Stage Least Squares. Os resultados obtidos pelos autores também apontaram para uma demanda elástica do 
álcool em relação ao preço tanto no período pré-flex, quanto no período pós-flex; no entanto, houve um aumento, a demanda ficou mais elástica ao preço do próprio bem e aos preços dos demais combustíveis. Assim, as elasticidades-preço do etanol e elasticidades-preço cruzada da demanda entre etanol e gasolina aumentaram com a entrada dos veículos flex-fuel no Brasil. No segundo caso, pode-se então sugerir, de acordo com os autores, que houve um aumento do grau de substituição entre os bens.

Também na abordagem de possíveis mudanças nas preferências dos consumidores, Souza (2010), fazendo uso de modelos com dados em painel, analisou a demanda por etanol e gasolina para o Brasil no período de 2001 a 2009 por unidades federativas (cross-section). No estudo, o autor utilizou como variáveis explicativas preços da gasolina, preços do etanol, consumo de energia elétrica como proxy para a renda, frota de veículos flex, frota de veículos movidos a álcool e variáveis binárias como controles. $\mathrm{O}$ autor buscou ainda testar a hipótese de que o crescimento da frota de veículos flex-fuel teria alterado o comportamento dos agentes consumidores. Tal hipótese de fato foi confirmada em parte com os resultados empíricos do modelo econométrico, no sentido em que se constatou um aumento da elasticidade-preço própria e cruzada para a gasolina e etanol. Embora ressalte-se que, próximo à paridade, em alguns casos, não se observou aumento das elasticidades.

Randow et al. (2010) estimaram as elasticidades-preço e renda da demanda por etanol no Brasil com dados (séries temporais) mensais para o período de julho de 2001 a outubro de 2009, usando modelos multivariados (VAR/ VEC). Concluíram que tal metodologia é apropriada para estimações e que o etanol e a gasolina podem ser considerados substitutos imperfeitos (somente no longo prazo) uma vez que a elasticidade-preço cruzada foi significativa do ponto de vista estatístico no longo prazo. Já no curto prazo, não existem evidências que os bens sejam substitutos (elasticidade-preço cruzada não significativa estatisticamente), este último resultado é pouco adequado ao que se observa no ponto de vista prático. Todavia, atestaram a existência de tendência que a demanda por etanol se torne mais volátil aos preços da gasolina no longo prazo. Com base nas defasagens do modelo, identificaram possíveis relações contemporâneas preço-renda-demanda, na medida em que tais variáveis defasadas em dois períodos, $(t-2)$ também determinam a demanda no período $t$.

Santos (2012) teve como objetivo estudar a sensibilidade da demanda por gasolina, etanol e gás natural comprimido no Brasil usando painéis dinâmicos para estimar as equações de demanda pelos combustíveis especificados e, assim, obter as elasticidades de curto e longo prazo. Concluíram que as demandas por gasolina e gás natural são inelásticas, enquanto o etanol possui demanda elástica. $\mathrm{O}$ autor enfatiza que a dinâmica do mercado de combustíveis no Brasil parece atrelar-se mais ao etanol que à gasolina e ressalta que a implementação da tecnologia flex-fuel afetou de modo significativo as forças de mercado por meio da sensibilidade dos agentes consumidores.

Cardoso et al. (2013), utilizando painéis espaciais dinâmicos, objetivaram captar as causas das flutuações da demanda por gasolina e etanol no Brasil. Os dados são por estado (cross-section) e no período de julho de 2001 a julho de 2011 (série temporal), compondo, desta forma, um painel balanceado totalizando uma amostra de 3.267 observações. Constataram que a demanda por etanol é elástica aos preços, enquanto a demanda por gasolina não é, no curto e longo prazo. Também ressaltaram que tanto a demanda por gasolina quanto a demanda por etanol têm influência maior dos preços da gasolina relativamente aos preços do etanol, o que pode ser útil para orientar possíveis políticas.

Cardoso e Bittencourt (2014) estimaram elasticidades-preço, renda e cruzada da demanda por etanol para o Brasil e por região, e seus resultados foram obtidos através de estimadores (GLS) General Least Squares com correção de heterocedasticidade no curto prazo e estimadores (DOLS) Dynamic Ordinary Least Squares no longo prazo. Os resultados apresentados mostraram que a 
demanda por etanol é elástica ao preço no curto e longo prazo e, com variáveis binárias, constataram o aumento das elasticidades-preço e cruzada da demanda após a implementação dos veículos flex-fuel. Os resultados encontrados por Cardoso e Bittencourt (2014) corroboram os resultados de Melo (2012), que apontaram os preços da gasolina como um dos fatores determinantes da demanda por álcool no curto prazo. Isto é, a demanda por álcool é sensível a choques no preço da gasolina no curto prazo.

De modo sucinto, pode-se elencar, com base em Cardoso et al. (2013), alguns estudos e seus respectivos resultados para o Brasil: Burnquist e Bacchi (2002) no período 1973-1998, elasticidade-preço da demanda por gasolina, (-0.23), elasticidade renda da demanda por gasolina, (0.96), Alves e Bueno (2003) no período 1974-1999, elasticidade-preço da demanda por gasolina, (-0.47), elasticidade renda da demanda por gasolina, (0.12), Roppa (2005) no período 1979-2000, elasticidade-preço da demanda por gasolina, (-0.63), elasticidade renda da demanda por gasolina, (0.16), Santos (2012), no período 2001-2011, elasticidade-preço da demanda por gasolina, (-0.78). Deste modo, parece haver um consenso na literatura nacional sobre a inelasticidade da demanda por gasolina ao preço próprio, assim como evidenciado internacionalmente.

Apesar de os resultados apresentados acima se reportarem ao curto prazo, tais características também se mantêm no longo prazo. Ademais, como a gasolina é um bem essencial, tais resultados estão de acordo com a teoria microeconômica. Diante deste panorama, espera-se encontrar neste estudo resultados semelhantes, embora o método, como dito anteriormente, seja diferente. Já com relação aos estudos da demanda por etanol, parece haver uma convergência sobre a classificação do bem com relação à alta volatilidade da demanda frente às flutuações no preço. Posto isto, a demanda por etanol é considerada elástica (FARINA et al., 2010; SERIGATI et al., 2010; RANDOW et al., 2010; SOUZA, 2010; SANTOS 2012; CARDOSO et al., 2013; CARDOSO e BITTENCOURT, 2014). Outra questão importante é o grau de substituição entre os combustíveis no geral, de acordo com Santos (2012), estes são considerados substitutos imperfeitos.

\section{Modelo linear approximation almost ideal demand system}

O (AIDS) Almost Ideal Demand System proposto por Deaton ${ }^{9}$ e Muellbauer (1980b) tem sido amplamente usado nos estudos empíricos para diversos produtos tanto na literatura nacional ${ }^{10}$ quanto internacional. O AIDS pode ser entendido como uma aproximação de primeira ordem para qualquer sistema de demanda (BARBOSA et al., 2013). Para desenvolver o sistema, os autores supõem preferências (PIGLOG) ${ }^{11}$ Price Independent Generalized Logarithmic, o que permite a agregação e possibilita a análise da demanda sob a perspectiva de um agente representativo racional (PEREDA, 2008). De acordo com Barbosa (2012), o modelo parte de uma função despesa classe de preferências PIGLOG - tal como especificada na equação 1 :

$$
\log [E(\mathrm{p}, U)]=(1-u) \log [a(\mathrm{p})]+u \log [b(p)]
$$

em que $u$ é a utilidade direta normalizada, isto é, $u \in[0,1]$, em que 0 é necessariamente o menor nível de utilidade e, consequentemente, 1 representa saciedade total e p é um vetor de preços, $a(\mathrm{p})$ e $b(\mathrm{p})$ são funções que para Pereda (2008) podem ser interpretadas como sendo o custo de

9. Laureado em 2015 com o Prêmio Sveriges Riksbank de Ciências Econômicas em Memória de Alfred Nobel.

10. Ver por exemplo: Garcia (1998), Asano e Fiuza (2001), Menezes et al. (2002), Pintos-Payeras e Cunha-Filho (2007).

11. De acordo com Coelho (2006), são os casos em que os gastos do agente representativo independem dos preços, dependendo somente da distribuição dos gastos. Estes são conhecidos na literatura como (PIGL) Price Independent Generalized Linearity. Assim, as funções despesas dos consumidores são dadas por: $E^{h}\left(p, u^{h}\right)=k^{h}\left[a(p)^{\alpha}\left(1-u^{h}\right)+b(p)^{\alpha} u^{h}\right]^{\frac{1}{\alpha}}$. Em que $k^{h}$ é um escalar que capta as diferenças entre os consumidores. E a função dispêndio do consumidor representativo é dada por: $E(p, u)=\left[a(p)^{\alpha}(1-u) b(p)^{\alpha} u\right]^{\frac{1}{\alpha}}$. Tomando a forma logarítmica chega-se a (PIGLOG) Price Independent Generalized Logarithmic. 
sobrevivência $[a(\mathrm{p})]$ e o custo da saciedade total ou prazer em nível máximo $[b(\mathrm{p})]$, e que assumem as seguintes formas, respectivamente:

$$
\begin{aligned}
& \log [a(p)]=\alpha_{0}+\sum_{i} \alpha_{i} \log \left(p_{i}\right)+ \\
& +\frac{1}{2} \sum_{i} \sum_{j} \gamma_{i j} \log \left(p_{i}\right) \log \left(p_{j}\right)
\end{aligned}
$$

e

$$
\begin{aligned}
& \log [b(p)]=\alpha_{0}+\sum_{i} \alpha_{i} \log \left(p_{i}\right)+ \\
& +\frac{1}{2} \sum_{i} \sum_{j} \gamma_{i j} \ln \left(p_{i}\right) \log \left(p_{j}\right)+\beta_{0} \prod_{i} p_{i}^{\beta_{i}}
\end{aligned}
$$

Deste modo, de (1), (2) e (3), tem-se:

$$
\begin{aligned}
& \log [E(p, U)]=\alpha_{0}+\sum_{i} \alpha_{i} \log \left(p_{i}\right)+ \\
& +\frac{1}{2} \sum_{i} \sum_{j} \gamma_{i j} \log \left(p_{i}\right) \log \left(p_{j}\right)+u \beta_{0} \prod_{i} p_{i}^{\beta_{i}}
\end{aligned}
$$

em que $\alpha_{i}, \gamma_{i j}$ e $\beta_{i}$ são parâmetros. Usando o lema de Shephard em (4) obtém-se:

$$
\begin{aligned}
& \frac{\partial \log [E(p, U)]}{\partial \log \left(p_{i}\right)}=\frac{p_{i} q_{i}}{E(p, U)}=w_{i}=\alpha_{i}+ \\
& +\sum_{i} \gamma_{i j} \log \left(p_{j}\right)+\beta_{i} u \beta_{0} \prod_{i} p_{i}^{\beta_{i}}
\end{aligned}
$$

Como no ótimo tem-se $E(p, U)=Y$, pode-se encontrar $u^{*}$, que é dado por:

$u^{*}=\left[\begin{array}{l}\log (Y)-\alpha_{0}+ \\ +\sum_{i} \alpha_{i} \log \left(p_{i}\right)+\frac{1}{2} \sum_{i} \sum_{j} \gamma_{i j} \log \left(p_{i}\right) \log \left(p_{j}\right)\end{array}\right] / \beta_{0} \prod_{i} p_{i}^{\beta_{i}}$

Substituindo $\quad u^{*} \quad$ em $\quad \partial \log [E(p, U)] / \partial \log \left(p_{i}\right)$, pode-se escrever a parcela dos gastos de $n$ produtos individualmente no gasto total como os logaritmos dos preços e da renda. Ademais, tal modelo preserva as propriedades da teoria do consumidor (propriedades da função demanda) ${ }^{12}$ (BARBOSA, 2012). Deste modo, partindo-se da

12. De acordo com Mas-Colell et al. (1995), são:

i) Satisfaz a lei de Walras (adding-up):

$$
\sum p_{l} x_{l}(p, w)=w
$$

ii) Homogênea de grau zero, então para todo $p$ e $w$ tem-se:

$$
\sum_{k=1}^{L} \frac{\partial x_{l}(p, w)}{\partial p_{k}} p_{k}+\frac{\partial x_{l}(p, w)}{\partial w} w=0 ; l=1, \ldots, L
$$

função despesa especificada, o modelo AIDS pode ser descrito como:

$$
w_{i}-\alpha_{i}+\sum_{j} \gamma_{i j} \log \left(p_{j}\right)+\beta_{i} \log \left(\frac{Y}{P}\right)
$$

em que $w_{i}$ representa a parcela dos gastos com o consumo do $i$-ésimo bem, $Y$ é o gasto total, isto é, $Y=\sum_{i=1}^{n} p_{i} q_{i}, p_{j}$ corresponde ao preço do $j$-ésimo bem e $P$ corresponde a um índice de preços que pode ser descrito da seguinte forma:

$$
\begin{aligned}
& \log P=\alpha_{0}+ \\
& +\sum_{i} \alpha_{i} \log \left(p_{i}\right)+\frac{1}{2} \sum_{i} \sum_{j} \gamma_{i j} \log \left(p_{i}\right) \log \left(p_{j}\right)
\end{aligned}
$$

em que a equação (7) satisfaz as restrições impostas pela teoria do consumidor dadas a seguir:

Restrições de aditividade

$$
\sum_{i} \alpha_{i}=1, \quad \sum_{i} \beta_{i}=0, \quad \sum_{i} \gamma_{i j}=0
$$

Restrições de Homogeneidade

$$
\sum_{j} \gamma_{i j}=0
$$

Restrições de Simetria

$$
\gamma_{i j}=\gamma_{j i}
$$

Em estudos empíricos, com objetivo de tornar o modelo linear, usa-se convencionalmente o índice de preços de Stone (CARDOSO, 2006; PINTOSPAYERAS, 2009; BARBOSA, 2012). Deaton e Muellbauer (1980a) sugerem que o NL-AIDS (não linear AIDS) com o índice de preços descrito acima pode ser aproximado pelo (LA-AIDS) ${ }^{13}$ Linear Approximation AIDS, de modo que:

iii) Agregação de Cournot:

$\sum_{l=1}^{L} p_{l} \frac{\partial x_{l}(p, w)}{\partial p_{k}}+x_{k}(p, w)=0 ; k=1, \ldots, L$

iv) Agregação de Engel:

$$
\sum_{l=1}^{L} p_{l} \frac{\partial x_{l}(p, w)}{\partial w}=1
$$

13. No caso do modelo linear, as elasticidades-preço Marshallianas são dadas por:

$$
\eta_{i j}=\frac{\partial w_{i}}{\partial \ln \left(p_{j}\right)} \frac{1}{w_{i}}-\delta_{i j}=\frac{\gamma_{i j}-\beta_{i}\left(w_{j}+\beta_{j} \ln \left(\frac{Y}{P}\right)\right)}{w_{i}}-\delta_{i j} \quad \forall i, j
$$




$$
\log P=\sum_{i=1}^{n} w_{i} \log \left(p_{i}\right)
$$

Para o caso em que os dados são de séries temporais, como neste artigo, Deaton e Muellbauer sugerem que o modelo deve ser estimado em diferenças, dado o problema de não estacionariedade e correlação serial. Deste modo, como descrito em Coelho (2006), diferenciando a equação (7) tem-se:

$$
d w_{i}=\sum_{i} \gamma_{i j} d \log \left(p_{j}\right)+\beta_{i}(d \log (Y)-d \log (P))
$$

em que:

$$
\begin{aligned}
& d \log (Y)=\sum_{j} w_{j} d \log \left(p_{j}\right)+\sum_{j} w_{j} d \log \left(q_{j}\right)= \\
& =d \log P+d \log Q
\end{aligned}
$$

Assim, a equação (13) torna-se:

$$
d w_{i}=\sum_{j} \gamma_{i j} d \log \left(p_{j}\right)+\beta_{i} d \log (Q)
$$

Para o processo de estimação deve-se transformar o modelo em diferenças finitas (COELHO, 2006):

$$
\Delta w_{i t}=\beta_{i} \Delta \log (Q)+\sum_{j} \gamma_{i j} \Delta \log \left(p_{j}\right)
$$

em que:

$$
\begin{aligned}
& \Delta w_{i t}=w_{i t}-w_{i(t-1)} \\
& \Delta \log (Q)=\sum_{i} w_{i t} \Delta \log \left(q_{i t}\right)
\end{aligned}
$$

Uma forma alternativa ${ }^{14}$ para trabalhar com série de tempo pode ser vista em Taljaard et al. (2004). Os autores usaram a substituição proposta

em que $\delta_{i j}$ é o delta de Kronecker, $\delta_{i j}=1$ se $i=j$, e $\delta_{i j}=0$ se $i \neq j$ (RESENDE FILHO et al., 2012). A elasticidade gasto é dada por:

$\eta_{i x}=\frac{\partial w_{i}}{\partial \ln (x)} \frac{1}{w_{i}}+1=\frac{\beta_{i}}{w_{i}}+1 \quad \forall i$

Usando as equações de Slutsky pode-se determinar as elasticidades-preço Hicksianas (compensadas), que são dadas por:

$\in_{i j}=\eta_{i j}+w_{j} \eta_{i x} \quad \forall i, j$

14. Neste caso, as elasticidades-preço marshallianas, hicksianas e elasticidade gasto podem ser obtidas de acordo com Taljaar et al. (2004), respectivamente por:

$$
\eta_{i, t}=\frac{\gamma_{i t}}{\overline{\bar{w}_{t}}}-\beta_{t}\left(\frac{\overline{w_{J}}}{\overline{\bar{w}_{l}}}\right)-\delta_{i j,} \quad i, j=1, \ldots, n
$$

por Eales e Unnevehr (1988) do índice de preços de Stone tradicional, por um índice no qual as parcelas do gasto são defasadas em um período para evitar problemas de simultaneidade. Deste modo, pode-se escrever o modelo da seguinte forma:

$$
\begin{aligned}
& w_{i t}=\alpha_{i}+\sum_{j} \gamma_{i j} \log \left(p_{j t}\right)+ \\
& +\beta_{i}\left(\log \left(Y_{t}\right)-\sum_{i=1}^{n} w_{i, t-1} \log \left(p_{i t}\right)\right)
\end{aligned}
$$

Assim, é preciso testar a estacionariedade das séries. Para tanto, foram utilizados os testes Augmented Dickey-Fuller - Teste ADF de Said e Dickey (1984) - e o Teste Phillips-Perron, de Phillips e Perron (1988). No primeiro, tem-se:

$$
\begin{aligned}
& \Delta Y_{t}=\mu-\left(1-\sum_{i=1}^{p} \psi_{i}\right) y_{t-1}+ \\
& +\sum_{i=1}^{p-1}\left(-\sum_{j=i}^{p-1} \psi_{j+1}\right) \Delta y_{t-1}+\in_{t}
\end{aligned}
$$

sendo $Y_{t}$ um processo $\operatorname{AR}(p)$ e $\in_{t} \sim R B\left(0, \sigma^{2}\right)$. O teste $\mathrm{ADF}$ tem como hipótese nula $H_{0}$, a não estacionariedade, então se procura a rejeição de $H_{0}$. Uma correção não paramétrica do teste DF foi proposta por Phillips e Perron (1988), em que não é preciso identificar a ordem do processo autorregressivo para expurgar a correlação serial dos resíduos, a hipótese nula do teste Phillips-Perron é a não estacionariedade (BUENO, 2011).

\subsection{Dados utilizados}

Os dados são de séries temporais e compreendem ao período do terceiro trimestre de 2001 (2001.T3) ao primeiro trimestre de 2015 (2015.T1), totalizando, desta forma, 55 observações em cada série da amostra para o estado de Pernambuco.

$$
\begin{aligned}
& \in_{i, t}=\frac{\gamma_{i t}}{\overline{\bar{w}_{t}}}-\delta_{i j}+\bar{w}_{J} \\
& \xi_{i}=\frac{\beta_{i}}{\overline{w_{i}}}+1
\end{aligned}
$$

em que $\gamma_{i t}$ e $\beta_{t}$ são parâmetros estimados via método (SUR) Seemingly Unrelated Regressions e $\overline{w_{t}}$ representa a despesa média. 
Tabela 1. Estatísticas descritivas

\begin{tabular}{ccccc}
\hline Variável & Média & Desvio Padrão & Mínimo & Máximo \\
\hline$p g c$ & 0,039 & 0,005 & 0,0314 & 0,0492 \\
peh & 0,0270 & 0,0023 & 0,0235 & 0,0351 \\
pde & 0,0282 & 0,0023 & 0,0249 & 0,03266 \\
pout & 72,7281 & 18,7024 & 38,7847 & 108,213 \\
qgc & $2,13 \mathrm{e}+08$ & $8,20 \mathrm{e}+07$ & $1,33 \mathrm{e}+08$ & $4,03 \mathrm{e}+08$ \\
qeh & $4,15 \mathrm{e}+07$ & $2,60 \mathrm{e}+07$ & $9,43 \mathrm{e}+06$ & $1,01 \mathrm{e}+08$ \\
qde & $2,79 \mathrm{e}+08$ & $8,33 \mathrm{e}+07$ & $1,83 \mathrm{e}+08$ & $5,11 \mathrm{e}+08$ \\
$x$ & $1,67 \mathrm{e}+008$ & $3,25 \mathrm{e}+07$ & $1,24 \mathrm{e}+008$ & $2,26 \mathrm{e}+08$ \\
\hline
\end{tabular}

Fonte: Elaboração própria.

O período foi escolhido de acordo com a disponibilidade dos dados. As séries usadas são preços da gasolina comum $(p g c)$, preços do etanol hidratado (peh), preços do óleo diesel (pde), quantidade vendida pelas distribuidoras, de gasolina comum $(q g c)$, etanol hidratado (qeh) e óleo diesel ( $q$ de). Além destas séries utilizou-se a série consumo das famílias $(x)$, representando o gasto total com bens de consumo, que foi usada para construir as séries das parcelas dos gastos com cada combustível analisado. A Tabela 1 apresenta as estatísticas descritivas das variáveis.

A série de gasto com cada combustível foi construída com base nas séries de preços e quantidades. A série do preço dos demais bens (pout) incluídos no sistema de demanda estimando foi construída nos moldes de Brester e Schroeder (1995) e usado por Resende Filho et al. (2012) ${ }^{15}$. As séries de preços e consumo foram deflacionadas pelo Índice Geral de Preços - Disponibilidade Interna (IGP-DI). Todas as séries, exceto o consumo das famílias, que foi obtida no IPEADATA, foram obtidas junto a Agência Nacional do Petróleo, Gás Natural e Biocombustíveis (ANP).

15. A partir da série trimestral do IGP-DI, gerou-se a série da seguinte forma: IGP $-D I_{t}=\sum_{i=4}^{4} p_{i t} w_{i t}$, resolvendo a equação para $p_{4 t}$, isto é, para o preço de todos os demais bens não incluídos no sistema de equações, em que $p_{i t}$ representa o preço do i-ésimo bem no período $t$ e $w_{i t}$ corresponde à parcela do gasto com o $i$-ésimo bem no período $t$.

\subsection{Modelo empírico}

Com base na equação (19) incorporando o termo de erro, o sistema de equações estimado é o seguinte:

$$
\begin{aligned}
& w_{i t}=\alpha_{i}+\sum_{j} \gamma_{i j} \ln \left(p_{j t}\right)+ \\
& +\beta_{i}\left(\ln \left(Y_{t}\right)-\sum_{i=1}^{n} w_{i, t-1} \ln \left(p_{i t}\right)\right)+\mu_{i t}
\end{aligned}
$$

em que $w_{i t}$ é a parcela do gasto com o bem $i$ ( $i=$ gasolina comum, etanol hidratado, óleo diesel e um bem agregado que representa todos os outros bens de consumo não incluídos explicitamente no sistema) no período $t(t=2001$.T3, ..., 2015.T1); $p_{j t}$ é o preço do bem $j ; Y_{t}$ é o consumo das famílias; $w_{i, t-1}$ é a parcela do gasto com o bem $i$ defasada em um período; $p_{i t}$ é o preço do bem $i$; e $\mu_{i t}$ é o termos de erro estocástico.

Como a soma das parcelas dos gastos é sempre igual a um, uma das quatro equações do sistema deve ser retirada para evitar problemas com a matriz de covariância, isto é, singularidade, tal procedimento é comum na literatura para esse tipo de modelo (RESENDE FILHO et al., 2012). Neste caso, optou-se por retirar a equação referente aos demais bens de consumo. O modelo descrito acima foi estimado pelo método SUR - Seemingly Unrelated Regressions, proposto por Zellner (1962) e Srivastava e Giles (1987), amplamente usado nas análises empíricas que estimaram o sistema de demanda quase ideal de Deaton e Muellbauer. De acordo com Barbosa et al. (2013), modelos de equações aparentemente não relacionadas são extensões do modelo de regressão 
linear, e podem ser entendidos como um sistema de várias equações de regressão com erros correlacionados.

\section{Análise dos resultados e discussão}

Nem todas as séries usadas neste estudo se mostraram estacionárias em nível, o que reforça a hipótese do uso do modelo em diferenças. Diante desta constatação, optou-se por utilizar as séries diferenciadas em primeira ordem. Com o objetivo de testar se as séries diferenciadas são de fato estacionárias, novamente recorreu-se aos testes ADF e Phillips-Perron. Os resultados dos testes estão nas Tabelas 2 e 3 , respectivamente.

Como pode ser visto na Tabela 2 , rejeita-se a hipótese nula para todas as séries, ou seja, todas as séries, exceto $x p 2$ (gasto total dividido pelo índice de preços construído com parcelas do gasto defasadas) que é estacionária em nível, são estacionárias em primeira diferença, de acordo com o teste ADF.

No intuito de corroborar os resultados deste teste, a Tabela 2 mostra que também é possível rejeitar a hipótese nula do teste Phillips-Perron.

Tabela 2. Teste ADF de raiz unitária

\begin{tabular}{cccccc}
\hline Variável & Estatística do teste & P- valor & Valor crítico: $\mathbf{1 \%}$ & Valor crítico: $\mathbf{5 \%}$ & Valor crítico: $\mathbf{1 0 \%}$ \\
\hline dlnpgc & $-8,165$ & 0,0000 & $-3,576$ & $-2,928$ & $-2,599$ \\
dlnpeh & $-6,217$ & 0,0000 & $-3,576$ & $-2,928$ & $-2,599$ \\
dlnpde & $-6,333$ & 0,0000 & $-3,576$ & $-2,928$ & $-2,599$ \\
dlnpout & $-6,379$ & 0,0000 & $-3,576$ & $-2,928$ & $-2,599$ \\
dwgc & $-10,250$ & 0,0000 & $-3,576$ & $-2,928$ & $-2,599$ \\
dweh & $-9,853$ & 0,0000 & $-3,576$ & $-2,928$ & $-2,599$ \\
dwde & $-7,775$ & 0,0000 & $-3,576$ & $-2,928$ & $-2,599$ \\
dwout & $-8,361$ & 0,0000 & $-3,576$ & $-2,928$ & $-2,599$ \\
xp2 & $-3,527$ & 0,0073 & $-3,576$ & $-2,928$ & $-2,599$ \\
\hline
\end{tabular}

Fonte: Elaboração própria a partir dos dados da pesquisa.

Tabela 3. Teste Phillips-Perron de raiz unitária

\begin{tabular}{|c|c|c|c|c|c|c|}
\hline Variável & \multicolumn{2}{|c|}{ Estatística do teste } & Valor crítico: $1 \%$ & Valor crítico: $5 \%$ & Valor crítico: $10 \%$ & P-valor \\
\hline \multirow{2}{*}{$d \operatorname{lnpgc}$} & Z(rho) & $-60,696$ & $-18,954$ & $-13,324$ & $-10,718$ & \multirow{2}{*}{0,0000} \\
\hline & $Z(t)$ & $-8,176$ & $-3,576$ & $-2,928$ & $-2,599$ & \\
\hline \multirow{2}{*}{ dlnpeh } & Z(rho) & $-46,357$ & $-18,954$ & $-13,324$ & $-10,718$ & \multirow{2}{*}{0,0000} \\
\hline & $Z(t)$ & $-6,230$ & $-3,576$ & $-2,928$ & $-2,599$ & \\
\hline \multirow{2}{*}{ dlnpde } & $\mathrm{Z}$ (rho) & $-47,949$ & $-18,954$ & $-13,324$ & $-10,718$ & \multirow{2}{*}{0,0000} \\
\hline & $Z(t)$ & $-6,343$ & $-3,576$ & $-2,928$ & $-2,599$ & \\
\hline \multirow{2}{*}{ dlnpout } & Z(rho) & $-47,305$ & $-18,954$ & $-13,324$ & $-10,718$ & \multirow{2}{*}{0,0000} \\
\hline & $\mathrm{Z}(\mathrm{t})$ & $-6,386$ & $-3,576$ & $-2,928$ & $-2,599$ & \\
\hline \multirow{2}{*}{$d w g c$} & $\mathrm{Z}$ (rho) & $-69,700$ & $-18,954$ & $-13,324$ & $-10,718$ & \multirow{2}{*}{0,0000} \\
\hline & $\mathrm{Z}(\mathrm{t})$ & $-10,388$ & $-3,576$ & $-2,928$ & $-2,599$ & \\
\hline \multirow{2}{*}{ dweh } & $\mathrm{Z}$ (rho) & $-71,005$ & $-18,954$ & $-13,324$ & $-10,718$ & \multirow{2}{*}{0,0000} \\
\hline & $\mathrm{Z}(\mathrm{t})$ & $-9,853$ & $-3,576$ & $-2,928$ & $-2,599$ & \\
\hline \multirow{2}{*}{ dwde } & Z(rho) & $-56,180$ & $-18,954$ & $-13,324$ & $-10,718$ & \multirow{2}{*}{0,0000} \\
\hline & $Z(t)$ & $-7,772$ & $-3,576$ & $-2,928$ & $-2,599$ & \\
\hline \multirow{2}{*}{ dwout } & $\mathrm{Z}$ (rho) & $-59,630$ & $-18,954$ & $-13,324$ & $-10,718$ & \multirow{2}{*}{0,0000} \\
\hline & $\mathrm{Z}(\mathrm{t})$ & $\begin{array}{r}-8,389 \\
\end{array}$ & $-3,576$ & $-2,928$ & $-2,599$ & \\
\hline \multirow{2}{*}{$x p 2$} & Z(rho) & $-12,226$ & $-18,954$ & $-13,324$ & $-10,718$ & \multirow{2}{*}{0,0074} \\
\hline & $\mathrm{Z}(\mathrm{t})$ & $-3,526$ & $-3,576$ & $-2,928$ & $-2,599$ & \\
\hline
\end{tabular}

Fonte: Elaboração própria a partir dos dados da pesquisa. 
Ressalta-se que outro fator importante que contribui para a adoção do modelo com séries diferenciadas é correção de possíveis problemas de autocorrelação serial, como destacado anteriormente. Mesmo que tal procedimento implique uma redução na amostra, os ganhos em termos de ajuste do modelo são significativos.

Assim como feito por Taljaard et al. (2004), que aplicou o modelo com dados da África do Sul sobre a demanda por carnes, verificou-se a possibilidade de as séries serem cointegradas. O resultado do teste de cointegração indica que as séries são cointegradas; deste modo, existe uma relação de longo prazo entre as variáveis aqui analisadas. O modelo especificado na equação (23) foi estimado pelo SUR restrito, ou seja, foram impostas as restrições destacadas anteriormente de simetria e homogeneidade. Deste modo, obtiveram-se os parâmetros necessários para o cálculo das elasticidades. Na Tabela 4 apresentam-se os resultados das estimações. Acrescenta-se ainda que, como destacado em seções anteriores, muitos trabalhos incluem dummies para captar os efeitos da implementação dos veículos flex-fuel. Seguindo este raciocínio, a partir do primeiro trimestre de 2003 a variável binária incluída (d1) assume valor igual a um e zero para períodos anteriores, tendo como objetivo controlar possíveis mudanças na demanda por combustíveis em função da implementação destes veículos.

A Tabela 5 apresenta as elasticidades calculadas com os parâmetros estimados utilizando as equações especificadas anteriormente. Como pode ser observado, as elasticidades para a demanda por gasolina comum, tanto a hicksiana quanto a marshalliana em valor absoluto são menores que 1 , indicando que a demanda por gasolina é inelástica ao próprio preço. Tal resultado está de acordo com os apresentados em Alves e Bueno (2003), Roppa (2005) e Santos (2012), que também obtiveram evidências sobre essa característica da demanda por gasolina.

Tabela 4. Estimações Seemingly Unrelated Regressions

\begin{tabular}{|c|c|c|c|c|c|}
\hline & Variáveis explicativas & Parâmetro estimado & Desvio Padrão & $\mathrm{Z}$ & $P>z$ \\
\hline \multirow{7}{*}{ qgc } & dlnpgc & $-0,008871$ & 0,0078658 & $-1,13$ & 0,259 \\
\hline & dlnpeh & 0,0179323 & 0,003345 & 5,36 & $0,000^{*}$ \\
\hline & dlnpde & $-0,0442165$ & 0,0083161 & $-5,32$ & $0,000^{*}$ \\
\hline & dlnpout & 0,0351552 & 0,0097267 & 3,61 & $0,000^{*}$ \\
\hline & $\mathrm{xp} 2$ & $-0,0135702$ & 0,0074692 & $-1,82$ & $0,069^{* *}$ \\
\hline & d1 & $-0,0032774$ & 0,0023529 & $-1,39$ & 0,164 \\
\hline & cons & 0,2063912 & 0,1139327 & 1,81 & $0,07^{* *}$ \\
\hline \multirow{7}{*}{ qeh } & dlnpgc & 0,0179323 & 0,003345 & 5,36 & $0,000^{*}$ \\
\hline & dlnpeh & $-0,0109318$ & 0,0024278 & $-4,5$ & $0,000^{*}$ \\
\hline & dlnpde & 0,0049975 & 0,00328 & 1,52 & 0,128 \\
\hline & dlnpout & $-0,0119979$ & 0,0033164 & $-3,62$ & $0,000^{*}$ \\
\hline & $\mathrm{xp} 2$ & $-0,0031634$ & 0,0024119 & $-1,31$ & 0,19 \\
\hline & d1 & $-0,0010163$ & 0,0007601 & $-1,34$ & 0,181 \\
\hline & cons & 0,0488329 & 0,0367849 & 1,33 & 0,184 \\
\hline \multirow{7}{*}{ qde } & dlnpgc & $-0,0442165$ & 0,0083161 & $-5,32$ & $0,000^{*}$ \\
\hline & dlnpeh & 0,0049975 & 0,00328 & 1,52 & 0,128 \\
\hline & dlnpde & 0,0205875 & 0,0127239 & 1,62 & 0,106 \\
\hline & dlnpout & 0,0186315 & 0,0161975 & 1,15 & 0,25 \\
\hline & $\mathrm{xp} 2$ & $-0,0126722$ & 0,0122087 & $-1,04$ & 0,299 \\
\hline & d1 & $-0,0039843$ & 0,0038272 & $-1,04$ & 0,298 \\
\hline & cons & 0,1937605 & 0,1862094 & 1,04 & 0,298 \\
\hline
\end{tabular}

* Significativo a $1 \%$, ** significativo a $10 \%$.

Fonte: Elaboração própria a partir dos dados da pesquisa. 
Tabela 5. Elasticidades estimadas

\begin{tabular}{lccc}
\hline & Elasticidade-preço compensada (Hicksiana) & Elasticidade-preço Marshalliana & Elasticidade Gasto \\
\hline Gasolina C & $-0,961452555$ & $-0,9953008$ & 0,713820224 \\
Etanol H & $-0,975760802$ & $-1,0077684$ & 0,498422231 \\
Óleo Diesel & $-0,93325909$ & $-0,9667403$ & 0,725433071 \\
\hline
\end{tabular}

Fonte: Elaboração própria a partir dos dados da pesquisa.

Com relação ao etanol, enquanto a elasticidade-preço compensada é menor que um em valor absoluto, a elasticidade-preço marshalliana é ligeiramente maior que um também em valor absoluto. Diante deste diagnóstico, somente o caso da elasticidade-preço marshalliana está de acordo com trabalhos como o de Randow et al. (2010), Souza (2010), Santos (2012), Cardoso et al. (2013) e Cardoso e Bittencourt (2014) que sugeriram que o etanol possui demanda elástica ao próprio preço. Quanto às elasticidades-preço para o óleo diesel, observa-se que em ambos os casos a demanda por tal combustível pode ser considerada inelástica. Dado o panorama descrito para o cenário nacional e estadual, esperava-se tal resultado para o diesel, já que se trata de um bem essencial e, como determina a teoria microeconômica, a demanda deve ser inelástica à volatilidade dos preços. Ademais, a série de preços para este bem se mostrou mais estável que as demais.

Neste contexto, o modelo parece descrever o comportamento da demanda, principalmente de gasolina e etanol, e sugerir resultados semelhantes às diversas metodologias já empregadas em outras pesquisas. Isto pode indicar que o modelo derivado por Deaton e Muellbauer é adequado para estudos deste mercado com ganhos em relação aos demais modelos tradicionalmente utilizados na literatura por estar respaldado em um modelo teórico consistente. Ressalta-se, entretanto, que alguns cuidados do ponto de vista técnico devem ser tomados no sentido de preservar características estatísticas aceitáveis. Uma possível estratégia seria aplicar alguns testes, como por exemplo o de quebra estrutural, como feito em Taljaard et al. (2004). Feito isso, e de posse dos períodos mais voláteis dos resíduos das equa- ções, incluir variáveis dummies para corrigir o problema no intuito de melhorar a qualidade do ajuste do modelo do ponto vista individual dos parâmetros.

\section{Considerações finais}

O presente estudo teve como objetivo estimar um sistema de demanda via modelo (LA-AIDS) Linear Approximation Almost Ideal Demand System por gasolina comum, etanol hidratado e óleo diesel para Pernambuco. Como descrito em seções anteriores, estes representam os três principais combustíveis na perspectiva de mercado. Dado o crescimento significativo da frota de veículos em Pernambuco, bem como a importância do modal rodoviário, modelar as características da demanda para estes bens pode ajudar na formulação de políticas públicas. Além disto, Pernambuco é um grande produtor de cana de açúcar, matéria-prima base para fabricação do etanol, combustível alternativo à gasolina e melhor sob vários aspectos já salientados. Assim, por esta óptica, conhecer melhor a demanda por etanol no estado também pode ser útil.

Os resultados aqui encontrados são semelhantes aos observados na literatura, no sentido em que apontam para a inelasticidade-preço da gasolina e diesel, o que é esperado dada a essencialidade destes bens. Evidências de que a gasolina possui demanda inelástica também foram encontradas em Burnquist e Bacchi (2002), Alves e Bueno (2003), Roppa (2005) e Santos (2012). Além disto, também foi possível sugerir, com base nas estimativas, que a demanda por etanol é elástica, por ter elasticidade-preço marshalliana 
maior que um em valor absoluto, convergindo para os resultados já encontrados em outros estudos como o de Farina et al. (2010), Serigati et al. (2010), Randow et al. (2010), Souza (2010), Santos (2012), Cardoso et al. (2013) e Cardoso e Bittencourt (2014).

Este estudo avança na literatura ao incorporar um modelo que preserva os pressupostos microeconômicos da teoria do consumidor possibilitando a ligação direta do modelo teórico com a estratégia empírica. Desta forma, os resultados encontrados podem auxiliar os policy makers na formulação de políticas direcionadas para este mercado no âmbito estadual. Cabe ressaltar ainda que as evidências obtidas através do LA-AIDS apontam para as mesmas características da demanda pelos bens analisados obtidas com métodos diferentes, como descrito na seção de revisão de estudos, o que de certo modo já era esperado, e pode sugerir que o modelo teórico e a estratégia de estimação se adequaram aos dados.

Extensões para esta pesquisa podem ser feitas com a inclusão de novas variáveis explicativas no sistema de demanda. Por exemplo, preços e quantidades demandadas dos demais combustíveis, frota de veículos e variáveis atreladas ao setor externo. Estas últimas têm o objetivo de controlar efeitos exógenos sobre a demanda. Ampliar a área geográfica de análise para outros estados, regiões e para o Brasil também é uma sugestão e compõe a agenda de pesquisas futuras. Com mesmo escopo de pesquisa, mas utilizando o sistema de demanda quase ideal não linear (NL-AIDS), que é uma extensão do modelo utilizado neste estudo, também é uma possível extensão desta pesquisa.

\section{Referências}

ALVES, D. C. O. e BUENO, R. L. S. Short-Run, LongRun and Cross Elasticities of Gasoline Demand in Brazil. Energy Economics, EUA, v. 25, p. 191-199, 2003.

ANNA, E. P. S. e BASTOS, J. C. A. Elasticidade da Demanda por Gasolina no Brasil e o Uso da Tecnologia Flex Fuel no Período 2001-2012. In: 41ํㅡㄹ Encontro Nacional ANPEC, Natal-RN, 2014.
ANP. Agência Nacional do Petróleo, Gás Natural e Biocombustíveis. Banco de dados. Disponível em: < http://www.anp.gov.br>. Acesso em: 23 nov. 2015.

ASANO, S. e FIUZA, E. P. S. Estimation of the Brazilian Demand System. IPEA, Rio de Janeiro, Discussion paper, n. 793, 2001.

BARBOSA, A. L. N. H. Ensaios Sobre Diferencial de Salários e Estimação de Demanda no Brasil. Tese (Doutorado em Economia) - FGV, Rio de Janeiro, 2012.

., MENEZES, T. A. e ANDRADE, B. C. Demanda por Produtos Alimentares nas Áreas Rurais e Urbanas do Brasil. Texto para Discussão, no 1829, IPEA, 2013.

BETARELLI JR., A. A. e DOMINGUES, E. P. Impactos Econômicos da Recente Política de Revisão Tarifária do Setor Ferroviário de Carga no Brasil (2013-2025). In: Encontro ANPEC, Foz do Iguaçú, PR. 2013.

BUENO, R. L. S. Econometria de Séries Temporais. 2. ed. rev. e atualiz. Ed. Cengage Learning, 2012. 360p.

BURNQUIST, H. L. e BACCHI, M. R. P. A Demanda por Gasolina no Brasil: Uma Análise Utilizando Técnicas de Co-integração. In: XL Congresso Brasileiro de Economia e Sociologia Rural, Equidade e Eficiência na Agricultura Brasileira. Passo Fundo, RS, 2002.

BRASIL. Empresa de Pesquisa Energética. Balanço Energético Nacional (BEN) - 2015. Ano base: 2014. Rio de Janeiro, 2015. Disponível em: <https://ben.epe.gov.br/ downloads/Relatorio_Final_BEN_2015.pdf $>$. Acesso em: 23 nov. 2015.

BRASIL, Ipeadata. Disponível em: <http://www. ipeadata.gov.br/>. Acesso em: 01 out. 2015.

. Ministério da Agricultura Pecuária e Abastecimento (MAPA). Disponível em: <http://www.agricultura.gov. br/>. Acesso em: 01 out. 2015.

BRESTER, G. W. e SCHROEDER, T. C. The impacts of brand and generic advertising on meat demand. American Journal of Agricultural Economics, v. 77, n. 4, p. 969-979, 1995.

BRITISH PETROLEUM (BP). Statistical Review of World Energy, 2016. Disponível em: <http://www.bp.com/ content $/ \mathrm{dam} / \mathrm{bp} / \mathrm{pdf} /$ energy-economics/statisticalreview-2016/bp-statistical-review-of-world-energy2016-full-report.pdf > . Acesso em: 28 jun. 2016.

CADE - Conselho Administrativo de Defesa Econômica. Cadernos do Cade, Brasília-DF, 2014.

CALLE, F. R. e WALTER, A. Global market for bioethanol: historical trends and future prospects. Energy for Sustainable Development, v. X, n. 1, 2006. 
CARDOSO, M. R. Avaliação da Simulação de Efeitos Unilaterais de Concentrações Horizontais: Uma Aplicação do Modelo PC-AIDS. Dissertação (Mestrado Profissional) Escola de Economia de São Paulo da Fundação Getúlio Vargas, São Paulo, Brasil, 2006.

CARDOSO, L. C. B., BITTENCOURT, M. V. L. e PORSSE, A. A. Demanda por Combustíveis Leves no Brasil: uma abordagem utilizando painéis espaciais dinâmicos. In: $41^{o}$ Encontro Nacional ANPEC, Foz do Iguaçú - PR, 2013.

. e BITTENCOURT, M. V. L. Mensuração das Elasticidades - preço da Demanda, Cruzada e Renda no Mercado de Etanol Brasileiro: um estudo usando painéis cointegrados. Revista de Economia e Sociologia Rural - RESR, Piracicaba-SP, v. 51, n. 4, p. 765-784, 2014.

CHEUNG, K-Y. e THOMSON, E. The Demand for Gasoline in China: A Cointegration Analysis. Taylor and Francis Journals, v. 31, n. 5, p. 533-544, 2004.

COELHO, A. B. A demanda de alimentos no Brasil, 2002/2003. Tese (Doutorado em Economia). Universidade Federal de Viçosa, Viçosa, 2006, 233p.

CORREA, A.S. e MINELA, A. Mecanismos nãoLineares de repasse cambial: um modelo de curva de Phillips com Threshold para o Brasil. In: XXXIII Encontro Nacional de Economia da ANPEC. Natal: Rio Grande do Norte, 2005.

COSTA, C. C. Formação de preços de açúcar e álcool combustível anidro e hidratado no Estado de São Paulo. Piracicaba 2001. Dissertação (Mestrado em Economia) - Escola Superior de Agricultura, Luiz de Queiroz, Universidade de São Paulo, 2001, 104p.

DAHL, C. A. e STERNER, T. N. S. Analysing gasoline demand elasticities: a survey. Energy Economics, n. 13, p. 1-210, 1991.

DEATON, A. e MUELLBAUER, J. An Almost Ideal Demand System. American Economic Review, v. 70, p. 312-336, 1980a.

. e MUELLBAUER, J. Economics and Consumer Behavior. Cambridge, England: Cambridge University Press, 1980b.

DENATRAN - Departamento Nacional de Trânsito. RENAVAM, Registro Nacional de Veículos Automotores. Disponível em: <http://www.denatran. gov.br/> . Acesso em: 25 nov. 2015.

DETRAN-PE - Departamento Estadual de Trânsito de Pernambuco. Disponível em: < http://www.detran. pe.gov.br/>. Acesso em: 10 nov. 2015.

EALES, J. S. e UNNEVEHR, L. J. Demand for beef and chicken products: Seperability and structural change.
American Journal of Agricultural Economics, n. 70, n. 3, p. 521-532, 1988.

ESPEY, M. Gasoline Demand Revisited: An International Meta-Analysis of Elasticities. Energy Economics, v. 20, p. 273-295, 1998.

FARINA, E., VIEGAS, C., LACERDA, P. e GARCIA, C. Mercado e Concorrência do Etanol. In: SOUSA, E. L. e MACEDO, I. C. (Orgs.). Etanol e Bioeletricidade: a cana de açúcar no futuro da matriz energética. São Paulo: Editora LUC, 2010, p. 226-311.

FREITAS, L. C. e KANEKO, S. Ethanol demand under the flex-fuel technology regime in Brazil. Energy Economics, v. 33, n. 6, p. 1146-1154, 2011.

GARCIA, R. B. Demanda por alimentos na região metropolitana de Porto Alegre: uma aplicação do Almost Ideal Demand System. 1998. (Dissertação de Mestrado) Porto Alegre, UFRGS.

GOLDEMBERG, J. e GUARDABASSI, P. The potential for first generation ethanol production from sugarcane. Wiley Interscience, p.17-24, 09 dez. 2009.

LIMA, R. C. e SAMPAIO, Y. Análise de estabilidade, transmissão e previsão do preço do açúcar. In: GALVÃO, O. J. A. Ensaios de economia. Recife: PIMES, 1997a.

MAIA, S. F., ROCHA, E. C. e LIMA, R.C. Elasticidade de Transmissão de Preços Usando Função de Transferência e Defasagens Distribuídas: Metodologias Comparadas. In: 37º Congresso SOBER. Foz do Iguaçu, Paraná, 1999.

MAPA, Ministério da Agricultura, Pecuária e Abastecimento. SAPCANA, Sistema de Acompanhamento de Produção Canavieira. Disponível em: <http://sistemasweb.agricultura.gov.br/>. Acesso em: 9 nov. 2015.

MAS-COLELL, A., WHINSTON, M. D. e GREEN, J. R. Microeconomic Theory. Oxford University Press, 1995.

MELO, A. S. Três ensaios sobre os mercados de gasolina, etanol e açúcar no Brasil. Tese (Doutorado em Economia) - Universidade Federal de Pernambuco, Recife, 2012. 103p.

MENEZES, T. et al. Gastos alimentares nas grandes regiões urbanas do Brasil: aplicação do modelo AID aos micro dados da POF 1995/1996. IBGE. Texto para Discussão, no 896, IPEA, 2002.

NAPPO, M. A Demanda por gasolina no Brasil: uma avaliação de suas elasticidades após a introdução dos carros bicombustível. Dissertação (Mestrado) - Escola de Economia de São Paulo da Fundação Getúlio Vargas, São Paulo, Brasil, 2007, 62p. 
PEREDA, P. C. Estimação das equações de demanda por nutrientes usando o modelo Quadratic Almost Ideal Demand System (QUAIDS). Dissertação (Mestrado em Economia). Universidade de São Paulo, São Paulo, 2008, 124p.

PHILLIPS, P. C. B. e PERRON, P. Testing For a Unit Root in Time Series Regression. Biomètrika, v. 75, n. 2, p. 335-46, 1988.

PINTOS-PAYERAS, J. A. Estimação do sistema quase ideal de demanda para uma cesta ampliada de produtos empregando dados da POF de 2002-2003. Economia Aplicada, v. 13, n. 2, p. 231-255, 2009.

e CUNHA-FILHO, J. H. Um sistema quase ideal de demanda para produtos alimentícios no Brasil. In $45^{\circ}$ Congresso da Sociedade Brasileira de Economia Administração e Sociologia Rural, Conhecimentos para Agricultura do Futuro. Londrina-PR, 2007.

RAMANATHAN, R. Short and long-run elasticities of gasoline demand in India: an empirical analysis using co-integration techniques. Energy Economics, v. 21, n. 4, p. 321-330, 1999.

RANDOW, B. M. V., FONTES, R. M. O. e CARMINATI, J. G. O. Estimativas das elasticidades-preço e renda da demanda por álcool combustível no Brasil. In: $48^{\underline{o}}$ Congresso da Sociedade Brasileira de Economia Administração e Sociologia Rural, Tecnologias, Desenvolvimento e Integração Social. Campo Grande MS, 2010.

RESENDE FILHO, M. A. et al. Sistemas de Equações de Demanda por Carnes no Brasil: especificação e estimação. Revista de Economia e Sociologia Rural - RESR, Piracicaba-SP, v. 50, n. 1, p. 033-050, jan./mar. 2012.

RODRIGUEZ,M.F.Estimación de la demanda de combustibles en República Dominicana. Secretariado Técnico de la Presidência - Unidad de Análisis Econômico. República Dominicana: Texto de Discusión 6.

ROPPA, B. F. Evolução do consumo de gasolina no Brasil e suas elasticidades: 1973 a 2003.64p. (Monografia)-Universidade Federal do Rio de Janeiro. Rio de Janeiro, RJ, 2005.

SAID, S. E. e DICKEY, D. A. Testing for Unit Roots in Autoregressive-Moving Average Models of Unknown Order. Biomètrika, v. 71, n. 3, p. 599-607, 1984.

SANTOS, G. F. Fuel demand in Brazil in a dynamics panel data approach. Energy Economics, v. 36, p. 229240, 2012.
.; FARIA, W. R. Spatial Panel Data Models and Fuel Demand in Brazil. Texto para Discussão Nereus 10-2012, Universidade de São Paulo. 2012.

SCHÜNEMANN, L. A demanda de gasolina automotiva no Brasil: o impacto nas elasticidades de curto e longo prazo da expansão do GNV e dos carros Flex. 2007. 91 p. Dissertação (Mestrado profissionalizante em Economia) Faculdade de Economia e Finanças do IBMEC, Rio de Janeiro, 2007.

SERIGATI, F. C., CORREIA, L. B. e PEROSA, B. B. O impacto dos veículos flex-fuel sobre o mercado de combustíveis no Brasil. In: 48ํㅡㅁ Congresso Brasileiro de Economia, Administração e Sociologia Rural, Tecnologias, Desenvolvimento e Integração Social. Campo Grande, MS. 2010.

SIGNORINI, G. e MARJOTTA-MAISTRO, M. C. Preços no Sudeste e no Nordeste. Agroanalysis, São Paulo-SP, p. 37-38, fev. 2007.

SILVA, C. C. Transmissão e assimetria nos preços do gás natural no mercado doméstico e no mercado internacional: uma abordagem de séries temporais. Dissertação. (Mestrado em Economia). Universidade Federal da Paraíba, Paraíba, 2008, 142p.

.et al. Investigando a Assimetria e Hysteresis nos preços dos combustíveis no mercado brasileiro: Uma abordagem através dos modelos Threshold e ARFIMA. In: Congresso Brasileiro de Economia, Administração e Sociologia Rural, 2010, Tecnologias, Desenvolvimento e Integração Social. Campo Grande, MS. 2010.

SRIVASTAVA, V. K. e GILES, D. E. A. Seemingly Unrelated Regression Equations Models. New York: Marcel Dekker Inc, 1987.

SOUZA, A. Estudo das Demandas de Etanol e Gasolina no Brasil no Período 2001 - 2009. Dissertação (Mestrado Profissional) - Escola de Economia de São Paulo da Fundação Getúlio Vargas, São Paulo, Brasil, 2010.

TALJAARD, P. R., ALEMU, Z. G. e SCHALKWYK, H. D. The Demand for Meat in South Africa: An Almost Ideal Estimation. Agrekon, v. 43, n. 4, p. 430-443, 2004.

ZELLNER, A. An Efficient Method of Estimating Seemingly Unrelated Regressions and Tests for Aggregation Bias. Journal of the American Statistical Association, v. 57, n. 298, p. 348-368, 1962. 